This is an Accepted Manuscript of an article published by Taylor \& Francis in Supramolecular Chemistry, which will be published in final form at:

http://www.tandfonline.com/toc/gsch20/current 
Rapid and simultaneous synthesis of a hydrogen bond templated [3]rotaxane and its related [2]rotaxane molecular shuttle

Nicholas H. Evans* and Geoffrey R. Akien

Department of Chemistry, Lancaster University, Lancaster, United Kingdom

Address: Department of Chemistry, Lancaster University, Lancaster, LA1 4YB. UK.

Telephone: + 0044 (0)1524 594538

Email: n.h.evans@lancaster.ac.uk

ORCID identifier: 0000-0002-5839-2655

Twitter: @Supra_Evans 


\title{
Rapid and simultaneous synthesis of a hydrogen bond templated [3]rotaxane and its related [2]rotaxane molecular shuttle
}

\author{
The rapid preparation and spectroscopic characterisation of a hydrogen bond \\ templated [3]rotaxane and its related [2]rotaxane is presented. VT NMR \\ spectroscopy confirms that the [2]rotaxane acts as a molecular shuttle. DFT \\ computational modelling provides some further insight into the non-covalent \\ interactions present within the rotaxane species.
}

Keywords: self-assembly; rotaxane; molecular shuttle; hydrogen bonding

\section{Introduction}

While the most celebrated nanotechnological application of [2]rotaxanes and [2]catenanes is that of molecular machines [1, 2], a range of useful functions of such interlocked molecules have been demonstrated [3], including their use as selective hosts and sensors for ionic and molecular guests [4]. 'Higher-order' interlocked structures (i.e. those consisting of more than two interlocked components) present further opportunities for such applications. For example, [3]rotaxane molecule shuttles have been prepared where the distance between the two rings may be varied reversibly $[5,6]$. Further, the ability of suitably designed [3]rotaxanes to bind guest species between the three interlocked components has also been demonstrated [7-9].

A focus of our research programme at Lancaster has been the investigation of hydrogen bond templated synthesis to rapidly prepare [2]catenane and [2]rotaxane species [10-12]. [3]Rotaxanes have already been prepared by others using a range of templating interactions [5-9, 13-20] - including examples consisting of two axles threaded through one macrocyclic component [21-23] - but comparatively few using neutral hydrogen bond templates, notable examples being reported by Vögtle [24, 25], and more recently by Simpkins [26] and Brouwer [27]. This communication presents 
the rapid preparation of both a [3]rotaxane and its related [2]rotaxane, by the use of a hydrogen bond templated synthetic strategy [12], that utilises copper catalysed alkyneazide cycloaddition (CuAAC) “click” chemistry to achieve interlocked structure formation [28-30]. The identities of both rotaxane species were confirmed by NMR spectroscopy and mass spectrometry. In $1: 1 \mathrm{CDCl}_{3} / \mathrm{CD}_{3} \mathrm{OD}$, the macrocycle of the [2]rotaxane translates rapidly between the two amides of the axle. DFT modelling provides some further insight into the inter-component hydrogen bonds present within both rotaxane species.

\section{Results and discussion}

\subsection{Synthesis}

The synthetic strategy to prepare a [3]rotaxane involves a previously reported pseudorotaxane [12]. Inspired by work reported by Philp [31] and Leigh [32], this consists of a simple amide half axle component (in our system this possesses an azide) threaded through a polyether-isophthalamide macrocycle. Reacting this pseudo-rotaxane with a bis-alkyne using CuAAC click reaction conditions, should generate the desired [3]rotaxane. Based on previous results, it was expected that in addition to the [3]rotaxane, the related [2]rotaxane would also be synthesised. By possessing only one macrocyclic ring but two amides on the axle, the [2]rotaxane could act as a molecular shuttle.

The actual synthesis undertaken is shown in Scheme 1. Macrocycle 1 [10] and 1.1 equivalents of azide 2 [12] were dissolved in dry $\mathrm{CH}_{2} \mathrm{Cl}_{2}$ under an inert atmosphere to allow for formation of the hydrogen bond templated pseudo-rotaxane. Then 0.55 equivalents of bis-alkyne 3 [33] was added, followed by catalytic $\mathrm{Cu}\left(\mathrm{CH}_{3} \mathrm{CN}\right)_{4} \mathrm{BF}_{4}$ and tris(benzyltriazolylmethyl)amine (TBTA), plus 1.2 equivalents of $N, N$ - 
diisopropylethylamine (DIPEA). After stirring the reaction mixture overnight and aqueous workup, separation of the [3]rotaxane 4 (18\% yield) and [2]rotaxane 5 (26\% yield) was achieved by preparative TLC [34]. While the isolated yields are modest, the rotaxanes have been obtained in short order considering the number of steps required to prepare the precursors (1: 3 steps, 2: 2 steps and 3: 1 step) from commercially available starting materials. To aid the interpretation of spectral data of rotaxanes $\mathbf{4}$ and $\mathbf{5}$, free axle 6 was also prepared by an analogous reaction in the absence of macrocycle $\mathbf{1}$ [35]. $<<$ Insert Scheme 1 near here $>>$

\subsection{Spectral characterisation}

The [3]rotaxane, [2]rotaxane and axle were all characterised by NMR and IR spectroscopy and mass spectrometry. The ${ }^{1} \mathrm{H}$ NMR spectra of the rotaxanes, along with those of the non-interlocked axle and macrocycle are displayed in Figure 1 [36]. The upfield shift and splitting of protons $f$ and $g$ in rotaxanes $\mathbf{4}$ and $\mathbf{5}$ compared to macrocycle $\mathbf{1}$ is consistent with intercalation of the axle component between the aromatic rings of the macrocycle. The downfield shift of proton $c$ in the rotaxanes is consistent with hydrogen bonding to the carbonyl oxygen of the axle amide. Further evidence of the interlocked nature of the rotaxanes is provided by the appearance of $[\mathrm{M}+\mathrm{H}]^{+}$and $[\mathrm{M}+\mathrm{Na}]^{+}$molecular ion peaks for each species in positive-ion electrospray mass spectra (see Supplemental Online Material). $<<$ Insert Figure 1 near here $>>$

The ${ }^{1} \mathrm{H}$ NMR spectrum of [2]rotaxane 5 shows that at $298 \mathrm{~K}$ in 1:1 $\mathrm{CDCl}_{3} / \mathrm{CD}_{3} \mathrm{OD}$ the rotaxane acts as a molecular shuttle [37-40]. In this hydrogen bond disrupting solvent system, motion of the macrocyclic ring between the two amides of the axle is fast on the NMR timescale, as evidenced by the axle protons being 
symmetrical. If the motion was slow then there would be twice as many resonances due to the different chemical environments experienced by the macrocycle being docked at one station and not the other. A related consequence is that protons $e$ and $h$ in the macrocycle are not split (as in the [3]rotaxane), due to the two faces of this component of the [2]rotaxane being equivalent on the NMR timescale. It is notable that the protons $s$ corresponding to the central hydroquinone part of the axle, have the same chemical shift in 4, $\mathbf{5}$ and $\mathbf{6}$. This is evidence of minimal interaction between the macrocycle(s) and the hydroquinone of the axle in both rotaxanes, and suggests the hydroquinone does not act as a distinct intermediate station in [2]rotaxane $\mathbf{5}$ when the macrocycle shuttles between the two amides.

By contrast ${ }^{1} \mathrm{H}$ spectra of 5 in $\mathrm{CDCl}_{3}$ gave substantially broader peaks at room temperature, so variable temperature (VT) NMR experiments were carried out to further probe any dynamic processes of the rotaxanes (Figure 2 and Supplemental Online Material). The temperature dependence of the ${ }^{1} \mathrm{H}$ spectra was relatively complex, but the simpler ${ }^{19} \mathrm{~F}$ spectra were much more informative (Figure 2) and provide strong supporting evidence for the shuttling of the macrocyclic ring of [2]rotaxane 5 from one amide of the axle to the other. At $324 \mathrm{~K}$, the $\mathrm{CF}_{3}$ appears as a single peak at $-62.8 \mathrm{ppm}$ with a linewidth (at half height, $v_{1 / 2}$ ) of $10 \mathrm{~Hz}$ due to relatively fast shuttling of the ring between the two axle amides. Lowering the temperature of the sample to $283 \mathrm{~K}$ increases the linewidth to $280 \mathrm{~Hz}$, and brings this motion into the intermediate exchange regime on the NMR timescale. Further decreases in temperature cause the singlet to divide into two resonances at -62.2 and $-62.6 \mathrm{ppm}$ with the same area, reaching the slow exchange limit at $\approx 233 \mathrm{~K}$. This was accompanied by the gradual appearance of new peaks in the ${ }^{1} \mathrm{H}$ spectra. The ${ }^{19} \mathrm{~F}$ peaks were still relatively broad at 6.5 and $5 \mathrm{~Hz}$ 
respectively, so it is quite likely that there additional more subtle dynamic processes occurring on the NMR timescale.

The presence of two rings in [3]rotaxane $\mathbf{4}$ prevents the main shuttling motion operating with [2]rotaxane 5, and potentially allows for more direct observation of these more subtle motions. Over the same temperature range there is a broadening of the single ${ }^{19} \mathrm{~F}$ resonance from $2.5 \mathrm{~Hz}$ at $308 \mathrm{~K}$ to $7 \mathrm{~Hz}$ at $263 \mathrm{~K}$, with no significant changes outside of this temperature range (see Supplemental Online Material) - apart from a general upfield shift of 5 ppb $\mathrm{K}^{-1}$ (in the ${ }^{19} \mathrm{~F}$ spectra of both $\mathbf{4}$ and $\mathbf{5}$ ). It is difficult to unambiguously assign this dynamic process, but hydrogen bonding interactions between the triazole and macrocycle may be playing a role [41].

\subsection{DFT modelling}

To provide more insight into the non-covalent interactions present within the rotaxane species, some preliminary computational modelling was undertaken. Density-functional theory (DFT) calculations were undertaken on both rotaxanes, using the Gaussian 09 program [42], with the B3LYP exchange-correlation functional [43-46] and 6-31G* basis set for all atoms.

The lowest calculated energy conformations of rotaxanes $\mathbf{4}$ and $\mathbf{5}$ are depicted in Figure 3, with other selected structures to be found in the Supplemental Online Material. In the lowest energy conformations the macrocyclic components are, as expected, participating in hydrogen bond interactions with amide functional groups of the axle components. However, closer inspection of these lowest energy structures reveals differences in the hydrogen bonding to the polyether oxygens of the macrocyclic components. In particular, for [3]rotaxane 4, the lowest energy conformation appears not to involve either triazole $\mathrm{C}-\mathrm{H}$ hydrogen bonding to polyether oxygen atoms, whereas in [2]rotaxane 5 , a triazole $\mathrm{C}-\mathrm{H}$ does participate in hydrogen bonding, in a 
manner consistent with what was previously observed in modelling of related [2]rotaxanes [12]. It is suggested that the close proximity of the two interlocked macrocycles in [3]rotaxane 4, is the origin of the differences in hydrogen bonding observed between [3]rotaxane 4 and [2]rotaxane 5 in silico. $<<$ Insert Figure 3 near here $>>$

\section{Conclusions}

It has been demonstrated that a [3]rotaxane may be prepared rapidly from readily accessible precursors utilizing a simple amide axle motif in a hydrogen bond templated synthetic strategy. As anticipated, the related [2]rotaxane that was isolated from the same reaction was found to act as a molecular shuttle. Preliminary computational modelling is consistent with the expectation that the macrocyclic component resides over the amide of the axle components in both rotaxanes, but with differences in secondary hydrogen bonding interactions possibly arising from the close proximity of the two macrocycles in the [3]rotaxane. Ongoing work in our laboratories is looking to construct other higher order mechanically interlocked molecular architectures and putting these to use in various supramolecular chemistry applications.

\section{Experimental section}

\subsection{Notes on synthetic experimental procedures}

Commercially available solvents and chemicals were used without further purification unless stated. Dry solvents, $\mathrm{NEt}_{3}$ and DIPEA were purchased dry and stored under an inert atmosphere. $\mathrm{Cu}\left(\mathrm{CH}_{3} \mathrm{CN}\right)_{4} \mathrm{BF}_{4}$ was stored in a desiccator over $\mathrm{P}_{4} \mathrm{O}_{10}$. Deionised water was used in all cases. The syntheses of macrocycle $\mathbf{1}$ and azide $\mathbf{2}$ have been previously reported $[10,12]$. Bis-alkyne 3 was prepared according to an adapted literature procedure [33]. 
Silica gel with a $60 \AA$ particle size was used as the stationary phase for column chromatography. Both analytical and preparatory TLC plates were examined under short wavelength $(\lambda=254 \mathrm{~nm})$ UV light.

IR spectra were recorded on an Agilent Technologies Cary 630 FTIR spectrometer. NMR spectra were acquired on a Bruker AVANCE III 400 equipped with a room temperature broadband observe probe (BBO), with data being assigned according to atom labels defined in Scheme 1 . All ${ }^{19} \mathrm{~F}$ spectra were acquired without ${ }^{1} \mathrm{H}$ decoupling as this had no effect on linewidths. Spectra at $298 \mathrm{~K}$ were referenced using residual solvent peaks. For $1: 1 \mathrm{v} / \mathrm{v} \mathrm{CDCl}_{3} / \mathrm{CD}_{3} \mathrm{OD}$ mixtures, setting TMS to $0 \mathrm{ppm}$ yields spectra with solvent chemical shifts of $7.59 \mathrm{ppm}\left(\mathrm{CHCl}_{3}\right), 4.65(\mathrm{OH})$, and 3.35 $\left(\mathrm{CD}_{2} \mathrm{H}\right)$. More conveniently, configuring TopSpin with a deuterium lock shift of 3.316 for $\mathrm{CD}_{3}$ gives correctly referenced ${ }^{1} \mathrm{H}$ spectra without the need for any manual rereferencing. On other hand, the same indirect referencing gives ${ }^{13} \mathrm{C}$ spectra with TMS $-0.63 \mathrm{ppm}, \mathrm{CDCl}_{3} 77.49$ and $\mathrm{CD}_{3} \mathrm{OD} 48.34 \mathrm{ppm}$. For ease of reproducibility these were re-referenced with TMS 0 ppm. ${ }^{1} \mathrm{H}$ and ${ }^{19} \mathrm{~F}$ VT spectra in $\mathrm{CDCl}_{3}$ were all referenced indirectly to the deuterium lock shift, without any effort made to correct for the temperature dependence of $\mathrm{CHCl}_{3}$ of $\approx-0.5 \mathrm{ppb} \mathrm{K}{ }^{-1}$ [47], or in other words, a difference of 0.05 ppm over the temperature range investigated. This is much smaller than the observed ${ }^{19} \mathrm{~F}$ chemical shift changes of ca. $0.55 \mathrm{ppm}$ for $\mathbf{4}$ and $0.64 \mathrm{ppm}$ for $\mathbf{5}$. All 1D spectra at $298 \mathrm{~K}$ and above were acquired with sample spinning, but owing to equipment constraints spectra at lower temperatures were acquired non-spinning. Mass spectra were recorded on a Shimadzu LCMS IT ToF instrument. Melting points were recorded on a Gallenkamp capillary melting point apparatus and are uncorrected. 


\subsection{Experimental procedures}

[3]Rotaxane 4 \& [2] rotaxane 5. Macrocycle 1 (40.0 mg, $0.084 \mathrm{mmol}$ ) and azide 2 (31.5 mg, $0.093 \mathrm{mmol}$ ) were dissolved in dry $\mathrm{CH}_{2} \mathrm{Cl}_{2}$ under an $\mathrm{Ar}$ (g) atmosphere. Then bis-alkyne 3 (8.6 mg, $0.046 \mathrm{mmol}), \mathrm{Cu}\left(\mathrm{CH}_{3} \mathrm{CN}\right)_{4} \mathrm{BF}_{4}(2.9 \mathrm{mg}, 0.0093 \mathrm{mmol})$, TBTA (4.9 mg, $0.0093 \mathrm{mmol}$ ) and DIPEA (18 $\mu \mathrm{L}, 13 \mathrm{mg}, 0.102 \mathrm{mmol}$ ) were added. The reaction was stirred at RT for $19 \mathrm{~h}$ under an $\mathrm{Ar}$ (g) atmosphere. Then, the reaction was diluted to $10 \mathrm{~mL}$, washed with $0.02 \mathrm{M}$ EDTA in $1 \mathrm{M} \mathrm{NH}_{3}(\mathrm{aq})$ solution $(2 \times 10 \mathrm{~mL})$ and brine $(1 \times 10 \mathrm{~mL})$. The organic layer was dried $\left(\mathrm{MgSO}_{4}\right)$, filtered and solvent removed in vacuo. The crude material was submitted to preparative TLC (two plates of repeated running of 98:2 $\mathrm{CH}_{2} \mathrm{Cl}_{2} / \mathrm{CH}_{3} \mathrm{OH}$, then one plate of repeated running 9:1 to 8:2 $\mathrm{CH}_{2} \mathrm{Cl}_{2} / \mathrm{CH}_{3} \mathrm{CN}$ ) to give [3] rotaxane 4 (14 mg, 18\%) and [2]rotaxane 5 (16 mg, 26\%) as yellow oily films.

Characterisation data for [3] rotaxane 4. $R_{\mathrm{f}}=0.65,2: 1 \mathrm{CH}_{2} \mathrm{Cl}_{2} / \mathrm{CH}_{3} \mathrm{CN} . \mathrm{v}_{\max } / \mathrm{cm}^{-1}$ (neat) $3320(\mathrm{~N}-\mathrm{H}), 3060(\mathrm{C}-\mathrm{H}), 2920(\mathrm{C}-\mathrm{H}), 2870(\mathrm{C}-\mathrm{H}), 1640(\mathrm{C}=\mathrm{O})$, 1520, 1510, $1460,1360,1280,1170,1130,1080,1030 . \delta \mathrm{H}\left(400 \mathrm{MHz} ; 1: 1 \mathrm{CDCl}_{3} / \mathrm{CD}_{3} \mathrm{OD}\right) 8.48(2 \mathrm{H}$, s, $\left.H^{\mathrm{c}}\right), 8.17\left(4 \mathrm{H}, \mathrm{s}, H^{\mathrm{l}}\right), 8.11\left(4 \mathrm{H}, \mathrm{dd},{ }^{3} J=7.9 \mathrm{~Hz}^{4} J=1.7 \mathrm{~Hz}, H^{\mathrm{b}}\right), 8.04\left(2 \mathrm{H}, \mathrm{s}, H^{\mathrm{k}}\right), 7.74$ $\left(2 \mathrm{H}, \mathrm{s}, H^{\mathrm{q}}\right), 7.59\left(1 \mathrm{H}, \mathrm{t},{ }^{3} J=7.9 \mathrm{~Hz}, H^{\mathrm{a}}\right), 6.89\left(4 \mathrm{H}, \mathrm{s}, H^{\mathrm{s}}\right), 6.88\left(8 \mathrm{H}, \mathrm{d},{ }^{3} J=8.0 \mathrm{~Hz}, H^{\mathrm{f}}\right)$, $6.71\left(8 \mathrm{H}, \mathrm{d},{ }^{3} J=8.0 \mathrm{~Hz}, H^{\mathrm{g}}\right), 4.90\left(4 \mathrm{H}, \mathrm{s}, H^{\mathrm{r}}\right), 4.47\left(4 \mathrm{H}, \mathrm{d},{ }^{2} J=14 \mathrm{~Hz}, H^{\mathrm{e}}\right), 4.35(4 \mathrm{H}, \mathrm{d}$, $\left.{ }^{2} J=14 \mathrm{~Hz}, H^{\mathrm{e}}\right), 4.25\left(4 \mathrm{H}, \mathrm{d},{ }^{2} J=10 \mathrm{~Hz}, H^{\mathrm{h}}\right), 4.07\left(4 \mathrm{H}, \mathrm{d},{ }^{2} J=10 \mathrm{~Hz}, H^{\mathrm{h}}\right), 3.92(4 \mathrm{H}, \mathrm{t}$, $\left.{ }^{3} J=7.2 \mathrm{~Hz}, H^{\mathrm{p}}\right), 3.55-3.71\left(8 \mathrm{H}, \mathrm{m}, H^{\mathrm{i}} \& H^{\mathrm{j}}\right), 2.73\left(4 \mathrm{H}, \mathrm{t},{ }^{3} J=8.0 \mathrm{~Hz}, H^{\mathrm{n}}\right), 1.65-1.72$ (4H, app quin, $\left.H^{0}\right)$. $\delta \mathrm{C}\left(100 \mathrm{MHz} ; 1: 1 \mathrm{CDCl}_{3} / \mathrm{CD}_{3} \mathrm{OD}\right) 168.8,165.6(2 \times C=\mathrm{O}), 154.2$, 138.6, 137.8, 137.3, 135.6, 132.9 (quar, ${ }^{2} J=34 \mathrm{~Hz}, \mathrm{ArCCF}_{3}$ ), 132.7, 130.5, 130.1, 129.9, 129.5, 128.6, 126.3, 125.9, 124.5 (quar, $\left.{ }^{1} J=271 \mathrm{~Hz}, C F_{3}\right), 117.1,74.9\left(C^{\mathrm{h}}\right)$, 72.2, 71.1, $63.1\left(C^{\mathrm{r}}\right), 49.3\left(C^{\mathrm{p}}\right), 45.5\left(C^{\mathrm{e}}\right), 38.6\left(C^{\mathrm{n}}\right), 30.1\left(C^{0}\right)$ - evidence of coincident 
peaks in aromatic region. $\delta \mathrm{F}\left(377 \mathrm{MHz} ; 1: 1 \mathrm{CDCl}_{3} / \mathrm{CD}_{3} \mathrm{OD}\right)-63.2 . \mathrm{m} / \mathrm{z}(\mathrm{ES}) 1815.6637$ $\left([\mathrm{M}+\mathrm{H}]^{+} \mathrm{C}_{92} \mathrm{H}_{91} \mathrm{~N}_{12} \mathrm{O}_{14} \mathrm{~F}_{12}\right.$ requires 1815.6581, i.e. + 3.1 ppm); $1837.6346\left([\mathrm{M}+\mathrm{Na}]^{+}\right.$ $\mathrm{C}_{92} \mathrm{H}_{90} \mathrm{~N}_{12} \mathrm{NaO}_{14} \mathrm{~F}_{12}$ requires 1837.6400 , i.e. - $\left.2.9 \mathrm{ppm}\right)$.

Characterisation data for [2] Rotaxane 5. $R_{\mathrm{f}}=0.80,2: 1 \mathrm{CH}_{2} \mathrm{Cl}_{2} / \mathrm{CH}_{3} \mathrm{CN} . \mathrm{v}_{\max } / \mathrm{cm}^{-1}$ (neat) $3320(\mathrm{~N}-\mathrm{H}), 3050(\mathrm{C}-\mathrm{H}), 2920(\mathrm{C}-\mathrm{H}), 2880(\mathrm{C}-\mathrm{H}), 1780,1650(\mathrm{C}=\mathrm{O}), 1530$, 1510, 1370, 1280, 1170, 1130, 1080, 1010. $\delta \mathrm{H}\left(400 \mathrm{MHz} ; 1: 1 \mathrm{CDCl}_{3} / \mathrm{CD}_{3} \mathrm{OD}\right) 8.45(1 \mathrm{H}$, s, $\left.H^{\mathrm{c}}\right), 8.27\left(4 \mathrm{H}, \mathrm{s}, H^{\mathrm{l}}\right), 8.10\left(2 \mathrm{H}, \mathrm{dd},{ }^{3} J=7.9 \mathrm{~Hz}^{4} J=1.7 \mathrm{~Hz}, H^{\mathrm{b}}\right), 8.03\left(2 \mathrm{H}, \mathrm{s}, H^{\mathrm{k}}\right), 7.86$ $\left(2 \mathrm{H}, \mathrm{s}, H^{\mathrm{q}}\right), 7.59\left(1 \mathrm{H}, \mathrm{t},{ }^{3} J=7.9 \mathrm{~Hz}, H^{\mathrm{a}}\right), 6.89\left(4 \mathrm{H}, \mathrm{s}, H^{\mathrm{s}}\right) 6.88\left(4 \mathrm{H}, \mathrm{d},{ }^{3} J=8.0 \mathrm{~Hz}, H^{\mathrm{f}}\right)$, $6.71\left(4 \mathrm{H}, \mathrm{d},{ }^{3} J=8.0 \mathrm{~Hz}, H^{\mathrm{g}}\right), 5.01\left(4 \mathrm{H}, \mathrm{s}, H^{\mathrm{r}}\right), 4.41\left(4 \mathrm{H}, \mathrm{s}, H^{\mathrm{e}}\right), 4.19\left(4 \mathrm{H}\right.$, br peak, $\left.H^{\mathrm{p}}\right)$, 4.17 (4H, s, $\left.H^{\mathrm{h}}\right), 3.59-3.67\left(8 \mathrm{H}, \mathrm{m}, H^{\mathrm{i}} \& H^{\mathrm{j}}\right), 3.08\left(4 \mathrm{H}\right.$, br s, $\left.H^{\mathrm{n}}\right), 1.95\left(4 \mathrm{H}\right.$, br s, $\left.H^{0}\right)$. $\delta \mathrm{C}\left(100 \mathrm{MHz} ; 1: 1 \mathrm{CDCl}_{3} / \mathrm{CD}_{3} \mathrm{OD}\right)$ 168.9, $166.2(2 \times C=\mathrm{O}), 154.2,138.6,137.7,137.5$, 135.6, 133.1 (quar, ${ }^{2} J=34 \mathrm{~Hz}, \mathrm{ArCCF}_{3}$ ), 132.6, 130.5, 130.2, 129.5, 129.4, 129.4 (sic), 126.0, 126.0 (sic), 124.5 (quar, $\left.{ }^{1} J=271 \mathrm{~Hz}, C F_{3}\right), 117.2,74.9\left(C^{\mathrm{h}}\right), 72.2,71.0,63.3$ $\left(C^{\mathrm{r}}\right), 49.4\left(C^{\mathrm{p}}\right), 45.5\left(C^{\mathrm{e}}\right), 38.5\left(C^{\mathrm{n}}\right), 30.6\left(C^{0}\right)$ - evidence of coincident peaks in aromatic region. $\delta \mathrm{F}\left(377 \mathrm{MHz} ; 1: 1 \mathrm{CDCl}_{3} / \mathrm{CD}_{3} \mathrm{OD}\right)-63.4 . \mathrm{m} / \mathrm{z}(\mathrm{ES}) 1341.4404\left([\mathrm{M}+\mathrm{H}]^{+}\right.$ $\mathrm{C}_{64} \mathrm{H}_{61} \mathrm{~N}_{10} \mathrm{O}_{9} \mathrm{~F}_{12}$ requires 1341.4426, i.e. $\left.-1.6 \mathrm{ppm}\right) ; 1363.4244\left([\mathrm{M}+\mathrm{Na}]^{+}\right.$ $\mathrm{C}_{64} \mathrm{H}_{60} \mathrm{~N}_{10} \mathrm{NaO}_{9} \mathrm{~F}_{12}$ requires 1363.4245 , i.e. $\left.-0.1 \mathrm{ppm}\right)$.

Axle 6. Azide 2 (40.0 mg, $0.118 \mathrm{mmol}$ ) and bis-alkyne 3 (10.9 mg, $0.0587 \mathrm{mmol}$ ) were dissolved in dry $\mathrm{CH}_{2} \mathrm{Cl}_{2}$ under an $\mathrm{Ar}(\mathrm{g})$ atmosphere. Then, $\mathrm{Cu}\left(\mathrm{CH}_{3} \mathrm{CN}\right)_{4} \mathrm{BF}_{4}(3.7 \mathrm{mg}$, $0.012 \mathrm{mmol}$ ), TBTA (6.2 mg, $0.0118 \mathrm{mmol}$ ) and DIPEA (22 $\mu \mathrm{L}, 17 \mathrm{mg}, 0.13 \mathrm{mmol}$ ) were added. The reaction was stirred at RT for $16 \mathrm{~h}$ under an $\mathrm{Ar}$ (g) atmosphere, during which time the reaction mixture went from a solution to a thick gel-like substance. A drop of $\mathrm{CH}_{3} \mathrm{OH}$ was added to solubilise the reaction mixture, then the reaction was diluted to $10 \mathrm{~mL}$ with $\mathrm{CH}_{2} \mathrm{Cl}_{2}$, washed with $0.02 \mathrm{M}$ EDTA in $1 \mathrm{M} \mathrm{NH}_{3}$ (aq) solution 
$(2 \times 10 \mathrm{~mL})$ and brine $(1 \times 10 \mathrm{~mL})$. The organic layer was dried $\left(\mathrm{MgSO}_{4}\right)$, filtered and solvent removed in vacuo. The crude material was purified by silica gel chromatography (98:2 $\left.\mathrm{CH}_{2} \mathrm{Cl}_{2} / \mathrm{CH}_{3} \mathrm{OH}\right)$ to give the title compound as a white solid (29 mg, 57\%). Mp $184-186^{\circ} \mathrm{C} . R_{\mathrm{f}}=0.20,98: 2 \mathrm{CH}_{2} \mathrm{Cl}_{2} / \mathrm{CH}_{3} \mathrm{OH} . v_{\max } / \mathrm{cm}^{-1}$ (neat) 3300 $(\mathrm{N}-\mathrm{H}), 3080(\mathrm{C}-\mathrm{H}), 2930(\mathrm{C}-\mathrm{H}), 2880(\mathrm{C}-\mathrm{H}), 1640(\mathrm{C}=\mathrm{O})$, 1550, 1510, 1460, 1380, 1280, 1230, 1160, 1120, 1050. $\delta \mathrm{H}(400 \mathrm{MHz}$; DMSO-D $) 9.03\left(2 \mathrm{H}, \mathrm{t},{ }^{3} J=5.4 \mathrm{~Hz}, H^{\mathrm{m}}\right)$, $8.49\left(4 \mathrm{H}, \mathrm{s}, H^{\mathrm{l}}\right), 8.31\left(2 \mathrm{H}, \mathrm{s}, H^{\mathrm{k}}\right), 8.24\left(2 \mathrm{H}, \mathrm{s}, H^{\mathrm{q}}\right), 6.96\left(4 \mathrm{H}, \mathrm{s}, H^{\mathrm{s}}\right), 5.06\left(4 \mathrm{H}, \mathrm{s}, H^{\mathrm{r}}\right)$, $4.46\left(4 \mathrm{H}, \mathrm{t},{ }^{3} J=7.0 \mathrm{~Hz}, H^{\mathrm{p}}\right), 2.10-2.17\left(4 \mathrm{H}\right.$, app quin, $\left.H^{0}\right)$. NB: $H^{\mathrm{n}}$ obscured by water peak at $\approx 3.3$ ppm. $\delta \mathrm{C}(100 \mathrm{MHz}$; DMSO-D $) 163.4(C=\mathrm{O}), 152.3(\mathrm{OArC}), 142.8$ (triazole $C$ ), $136.5(\operatorname{ArCC}=\mathrm{O}), 130.4$ (quar, $\left.{ }^{2} J=33 \mathrm{~Hz}, \operatorname{ArCCF}_{3}\right), 128.0\left(C^{\mathrm{l}}\right), 124.8\left(C^{\mathrm{k}}\right)$, 124.5 $\left(C^{\mathrm{q}}\right), 123.1$ (quar, $\left.{ }^{1} J=271 \mathrm{~Hz}, C \mathrm{~F}_{3}\right), 115.6\left(C^{\mathrm{s}}\right), 61.6\left(C^{\mathrm{r}}\right), 47.3\left(C^{\mathrm{p}}\right), 36.9\left(C^{\mathrm{n}}\right)$, $29.5\left(C^{0}\right) . \delta \mathrm{F}(377 \mathrm{MHz}$; DMSO-D $)-61.3 . \mathrm{m} / \mathrm{z}(\mathrm{ES}) 867.2232\left([\mathrm{M}+\mathrm{H}]^{+}\right.$ $\mathrm{C}_{36} \mathrm{H}_{31} \mathrm{~N}_{8} \mathrm{O}_{4} \mathrm{~F}_{12}$ requires 867.2271, i.e. $\left.-4.5 \mathrm{ppm}\right) ; 889.2079\left([\mathrm{M}+\mathrm{Na}]^{+}\right.$ $\mathrm{C}_{36} \mathrm{H}_{30} \mathrm{~N}_{8} \mathrm{NaO}_{4} \mathrm{~F}_{12}$ requires 889.2091, i.e. -1.4 ppm).

\section{Funding details}

This work was supported by Lancaster University, in part through a Faculty of Science Technology Research Grant.

\section{Disclosure statement}

No potential conflict of interest is reported by the author.

\section{Acknowledgements}

Appreciation is expressed to the following: Lancaster University for financial support of this project; Dr David Rochester (Lancaster University) for the recording of mass spectrometry data and Dr Michael Peach (Lancaster University) for assistance with 
computational modelling. All underlying data for this paper are provided in the experimental section and the supplemental online material. Electronic copies of NMR files (including fid files) and computational log output files are available from DOI: 10.17635/lancaster/researchdata/177.

\section{Supplemental online material}

Copies of spectral data and further details of computational modelling can be accessed at $<<$ insert Springer hyperlink $>>$.

\section{References}

(1) https://www.nobelprize.org/nobel_prizes/chemistry/laureates/2016/

(2) Kay, E. R.; Leigh, D. A. Angew. Chem. Int. Ed. 2015, 54, 10080-10088.

(3) van Dongen, S. F. M.; Cantekin, S.; Elemans, J. A. A. W.; Rowan, A. E.; Nolte, R. J. M. Chem. Soc. Rev. 2014, 43. 99-122.

(4) Langton, M. J.; Beer, P. D. Acc. Chem. Res. 2014, 47, 1935-1949.

(5) Huang, T. J.; Brough, B.; Ho, C.-M.; Liu, Y.; Flood, A. H.; Bonvallet, P. A.; Tseng, H.-R.; Stoddart, J. F.; Baller M.; Maganov, S. Appl. Phys. Lett. 2004, 85, 5391-5393.

(6) Jiang, Q.; Zhang, H.-Y.; Han, M.; Ding, A.-J.; Liu, Y. Org. Lett. 2010, 12, 17281731.

(7) Collin, J.-P.; Frey, J.; Heitz, V.; Sauvage, J.-P.; Tock, C.; Allouche, L. J. Am. Chem. Soc. 2009, 131, 5609-5620.

(8) Evans, N. H.; Serpell, C. J.; Beer, P. D. Chem. Commun. 2011, 47, 8775-8777.

(9) Barendt, T. A.; Docker, A.; Marques, I.; Félix, V.; Beer, P. D. Angew. Chem. Int. Ed. 2016, 55, 11069-11076.

(10) Marrs, C. N.; Evans, N. H. Org. Biomol. Chem. 2015, 13, 11021-11025. 
(11) Evans, N. H.; Gell, C. E.; Peach, M. J. G. Org. Biomol. Chem. 2016, 14, 79727981.

(12) Fletcher, B. E.; Peach, M. J. G; Evans, N. H. Org. Biomol. Chem. 2017, 15, $2797-$ 2803.

(13) Chambron, J.-C.; Heitz, V.; Sauvage, J.-P. J. Am. Chem. Soc. 1993, 115, 1237812384.

(14) Amabilino, D. B.; Ashton, P. R.; Bělohradský, M.; Raymo, F. M.; Stoddart, J. F. J. Chem. Soc., Chem. Commun., 1995, 747-750.

(15) Ashton, P. R.; Glink, P. T.; Stoddart, J. F.; Tasker, P. A.; White, A. J. P.; Williams, D. J. Chem. Eur. J., 1996, 2, 729-736.

(16) Anderson, S.; Anderson, H. A. Angew. Chem. Int. Ed. Engl., 1996, 35, 1956-1959.

(17) Jiang, W.; Winkler, H. D. F.; Schalley, C. A. J. Am. Chem. Soc., 2008, 130, 1385213853.

(18) Fuller, A.-M. L.; Leigh, D. A.; Lusby, P. J. J. Am. Chem. Soc., 2010, 132, 49544959.

(19) Lee, S.; Chen, C.-H.; Flood, A. H. Nature Chem., 2013, 5, 704-710.

(20) Neal, E. A.; Goldup, S. M. Chem. Sci., 2015, 6, 2398-2404.

(21) Klotz, E. J. F.; Claridge, T. D. W.; Anderson, H. L. J. Am. Chem. Soc., 2006, 128, 15374-15375.

(22) Prikhod'ko, A. I.; Durola, F.; Sauvage, J.-P. J. Am. Chem. Soc., 2008, 130, 448449.

(23) Goldup, S. M.; Leigh, D. A.; McGonigal, P. R.; Ronaldson, V. E.; Slawin, A. M. Z. J. Am. Chem. Soc., 2010, 132, 315-320.

(24) Vögtle, F.; Dünnwald, T.; Händel, M.; Jäger, R.; Meier, S.; Harder, G. Chem. Eur. J. 1996, 2, 640-643. 
(25) Schmieder, R.; Hübner, G.; Seel, C.; Vögtle, F. Angew. Chem. Int. Ed. 1999, 38, 3528-3530.

(26) Simpkins, N. S.; Weske, D. F.; Male, L.; Coles, S. J.; Pitak, M. B. Chem. Commun. 2013, 49, 5010-5012.

(27) Jagesar, D. C.; Wiering, P. G.; Kay, E. R.; Leigh, D. A.; Brouwer, A. M.

ChemPhysChem, 2016, 17 1902-1912.

(28) Aprahamian, I.; Milijanic, O. Š.; Dichtel, W. R.; Isoda, K. Bull. Chem. Soc. Jpn. 2007, 80, 1856-1869.

(29) Hänni, K. D.; Leigh, D. A. Chem. Soc. Rev. 2010, 39, 1240-1251.

(30) Fahrenbach, A. C.; Stoddart, J. F. Chem - Asian J. 2011, 6, 2660-2669.

(31) Vidonne, A.; Philp, D. Tetrahedron 2008, 64, 8464-8475.

(32) Leigh, D. A.; Thomson, A. R. Org. Lett. 2006, 8, 5377-5379.

(33) Bi, J.; Zeng, X.; Tian, D.; Li, H. Org. Lett. 2016, 18, 1092-1095.

(34) It is almost certain some axle $\mathbf{6}$ was also produced in the rotaxane forming reaction. However, pure axle $\mathbf{6}$ was not isolated from the crude reaction mixture. It is not possible to determine the amount of axle $\mathbf{6}$ formed from the crude ${ }^{1} \mathrm{H}$ NMR spectrum, due to spectral complexity. It should also be noted that axle $\mathbf{6}$ gels in $\mathrm{CDCl}_{3}$ - the solvent used to record the crude ${ }^{1} \mathrm{H}$ NMR spectrum.

(35) The surprisingly low isolated yield of axle $\mathbf{6}$ from reacting two equivalents of azide $\mathbf{2}$ and one equivalent of bis-alkyne $\mathbf{3}$ is attributed to poor solubility properties of axle $\mathbf{6}$. (36) As discussed above, axle 6 forms a gel in pure $\mathrm{CDCl}_{3}$. The choice of $1: 1$ $\mathrm{CDCl}_{3}: \mathrm{CD}_{3} \mathrm{OD}$ allows for comparison of the ${ }^{1} \mathrm{H}$ NMR spectra of axle $\mathbf{6}$, macrocycle $\mathbf{1}$ and rotaxanes $\mathbf{4}$ and $\mathbf{5}$ with sharp, well-resolved peaks in all cases.

(37) Anelli, P. L.; Spencer, N.; Stoddart, J. F. J. Am. Chem. Soc. 1991, 113, 5131-5133.

(38) Lane, A. S.; Leigh, D. A.; Murphy, A. J. Am. Chem. Soc. 1997, 119, 11092-11093. 
(39) Cao, J.; Fyfe, M. C.; Stoddart, J. F.; Cousins, G. R. L.; Glink, P. T. J. Org. Chem. 2000, 65, 1937-1946.

(40) Aucagne, V.; Berná, J.; Crowley, J. D.; Goldup, S. M.; Hänni, K. D.; Leigh, D. A.; Lusby, P.; Ronaldson, V. E.; Slawin, A. M. Z.; Viterisi, A.; Walker, B. A. J. Am. Chem. Soc. 2007, 129, 11950-11963.

(41) In related [2]rotaxanes containing one amide and one triazole in the axle component, evidence of a possible triazole-polyether $\mathrm{C}-\mathrm{H} \cdots \mathrm{O}$ hydrogen bond was established (see Ref 12). One reviewer of a previous version of this manuscript pointed out that a triazole has been shown to act as a distinct station in a rotaxane molecular switch, see: Zheng, H.; Zhou, W.; Lv, J.; Yin, X.; Li, Y.; Liu, H.; Li, Y. Chem. Eur. J. 2009, 15, 13253-13262. However, based on previous computational modelling results (see Ref 12) this is believed to be unlikely in this case.

(42) Frisch, M. J.; Trucks, G. W.; Schlegel, H. B.; Scuseria, G. E.; Robb, M. A.;

Cheeseman, J. R.; Scalmani, G.; Barone, V.; Mennucci, B.; Petersson, G. A.; Nakatsuji, H.; Caricato, M.; Li, X.; Hratchian, H. P.; Izmaylov, A. F.; Bloino, J.; Zheng, G.; Sonnenberg, J. L.; Hada, M.; Ehara, M.; Toyota, K.; Fukuda, R.; Hasegawa, J.; Ishida, M.; Nakajima, T.; Honda, Y.; Kitao, O.; Nakai, H.; Vreven, T.; Montgomery, Jr., J. A.; Peralta, J. E.; Ogliaro, F.; Bearpark, M.; Heyd, J. J.; Brothers, E.; Kudin, K. N.; Staroverov, V. N.; Kobayashi, R.; Normand, J.; Raghavachari, K.; Rendell, A.; Burant, J. C.; Iyengar, S. S.; Tomasi, J.; Cossi, M.; Rega, N.; Millam, J. M.; Klene, M.; Knox, J. E.; Cross, J. B.; Bakken, V.; Adamo, C.; Jaramillo, J.; Gomperts, R.; Stratmann, R. E.; Yazyev, O.; Austin, A. J.; Cammi, R.; Pomelli, C.; Ochterski, J. W.; Martin, R. L.; Morokuma, K.; Zakrzewski, V. G.; Voth, G. A.;

Salvador, P.; Dannenberg, J. J.; Dapprich, S.; Daniels, A. D.; Farkas, Ö.; Foresman, J. B.;

Ortiz, J. V.; Cioslowski, J.; Fox, D. J. Gaussian 09, Revision E.01, Gaussian, Inc., Wallingford Ct, 2009. 
(43) Becke, A. D. J. Chem. Phys. 1993, 98, 5648-5652.

(44) Stephens, P. J., Devlin, F. J.; Chabalowski, C. F.; Frisch, M. J. J. Phys. Chem. 1994, 98, 11623-11627.

(45) Becke, A. D., J. Chem. Phys. 1993, 98, 1382-1377.

(46) Lee, C.; Yang, W.; Parr, E. G. Phys. Rev. B: Condens. Matter, 1998, 37, 785-789.

(47) Hoffman, R. E.; Becker, E. D. J. Magn. Reson., 2005, 176, 87-98. 

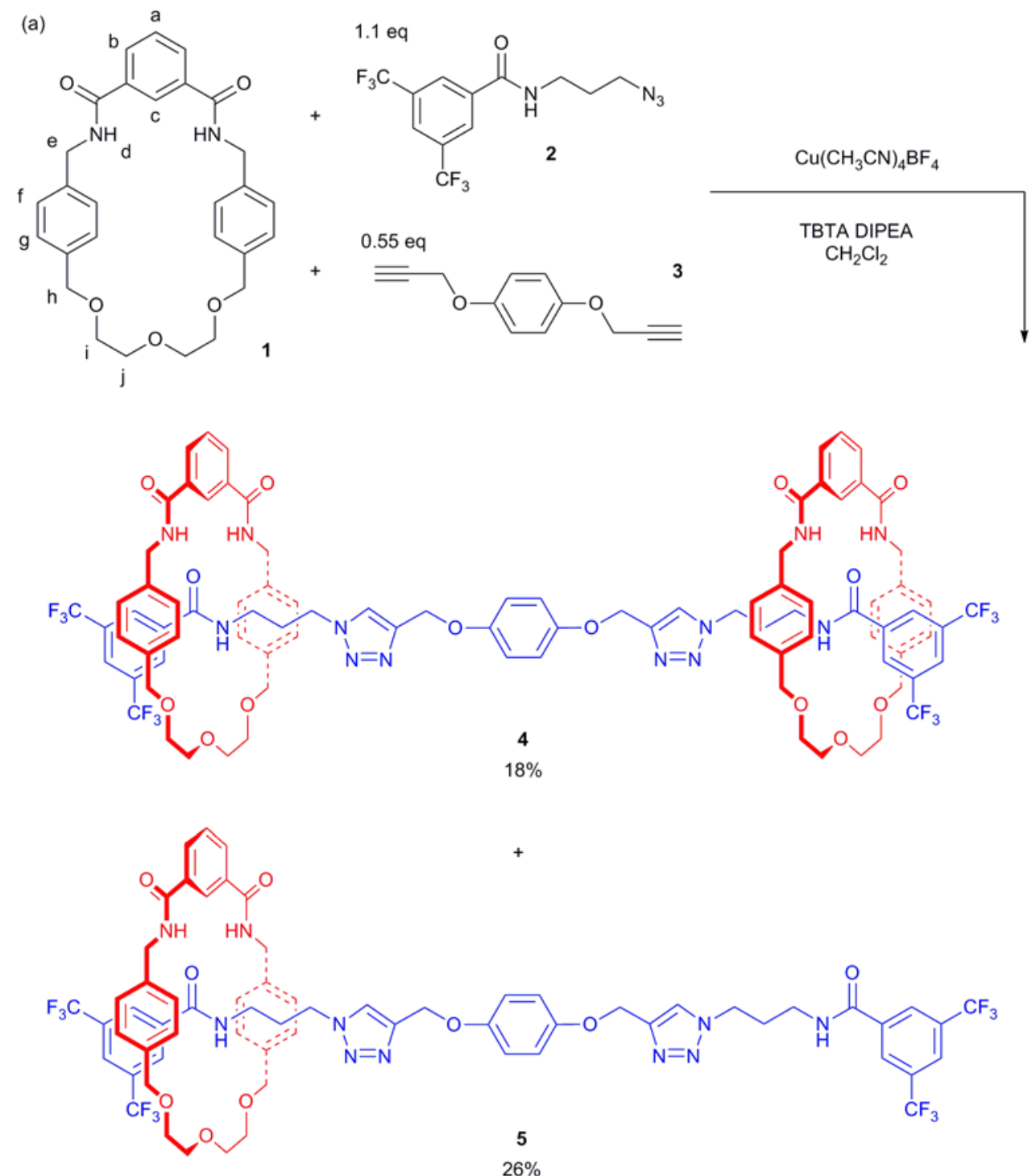

(b)

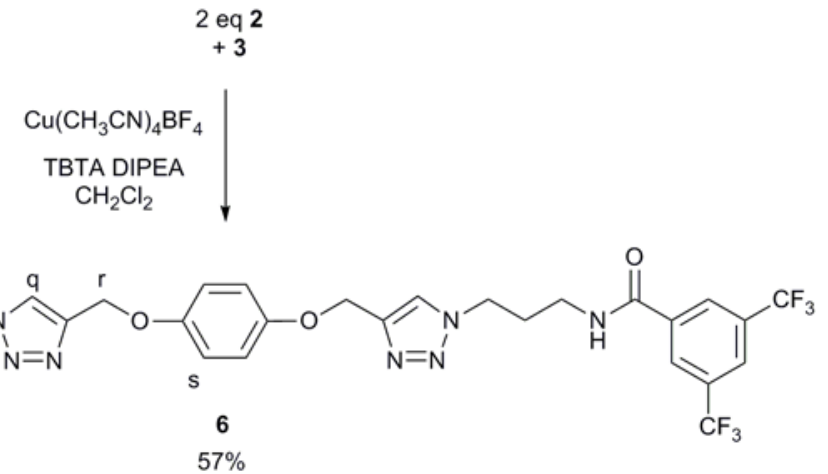

Scheme 1. Synthesis of (a) [3] rotaxane 4 and [2]rotaxane 5 and (b) axle 6. 


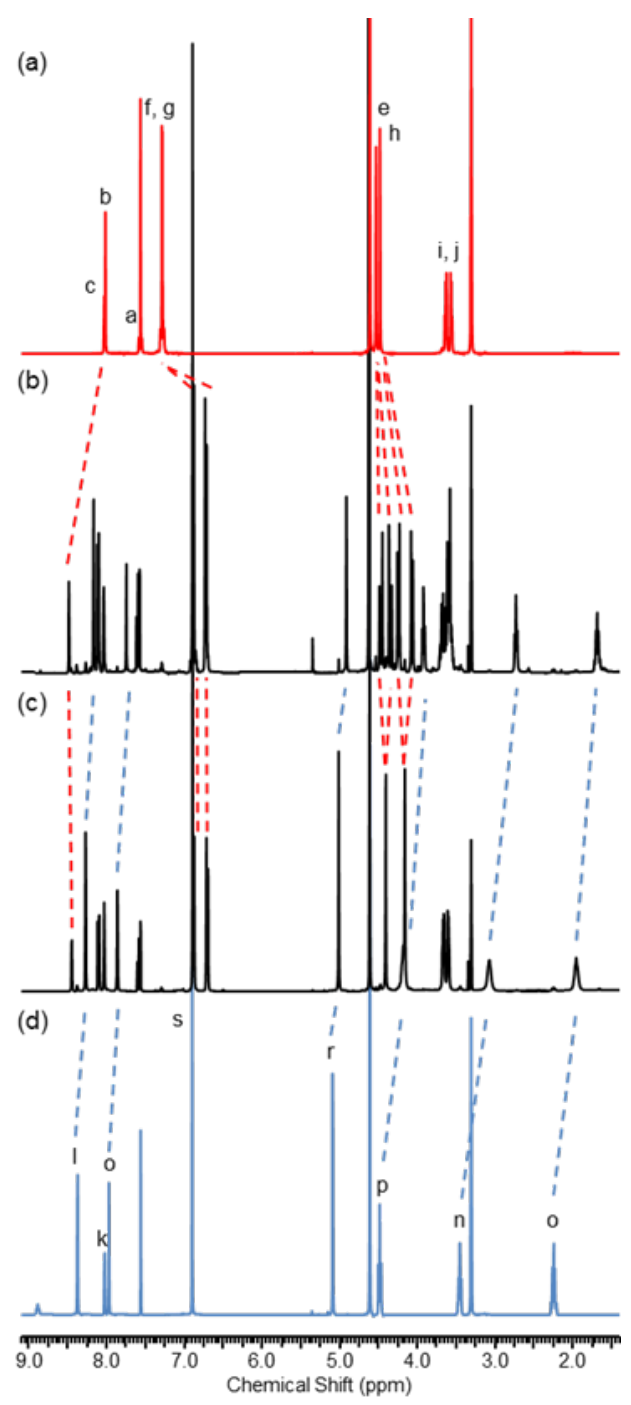

Figure 1. ${ }^{1} \mathrm{H}$ NMR spectra of (a) macrocycle 1, (b) [3]rotaxane 4, (c) [2]rotaxane 5 and (d) axle 6 (1:1 $\left.\mathrm{CDCl}_{3} / \mathrm{CD}_{3} \mathrm{OD}, 400 \mathrm{MHz}, 298 \mathrm{~K}\right)$. For atom labels see Scheme 1. 


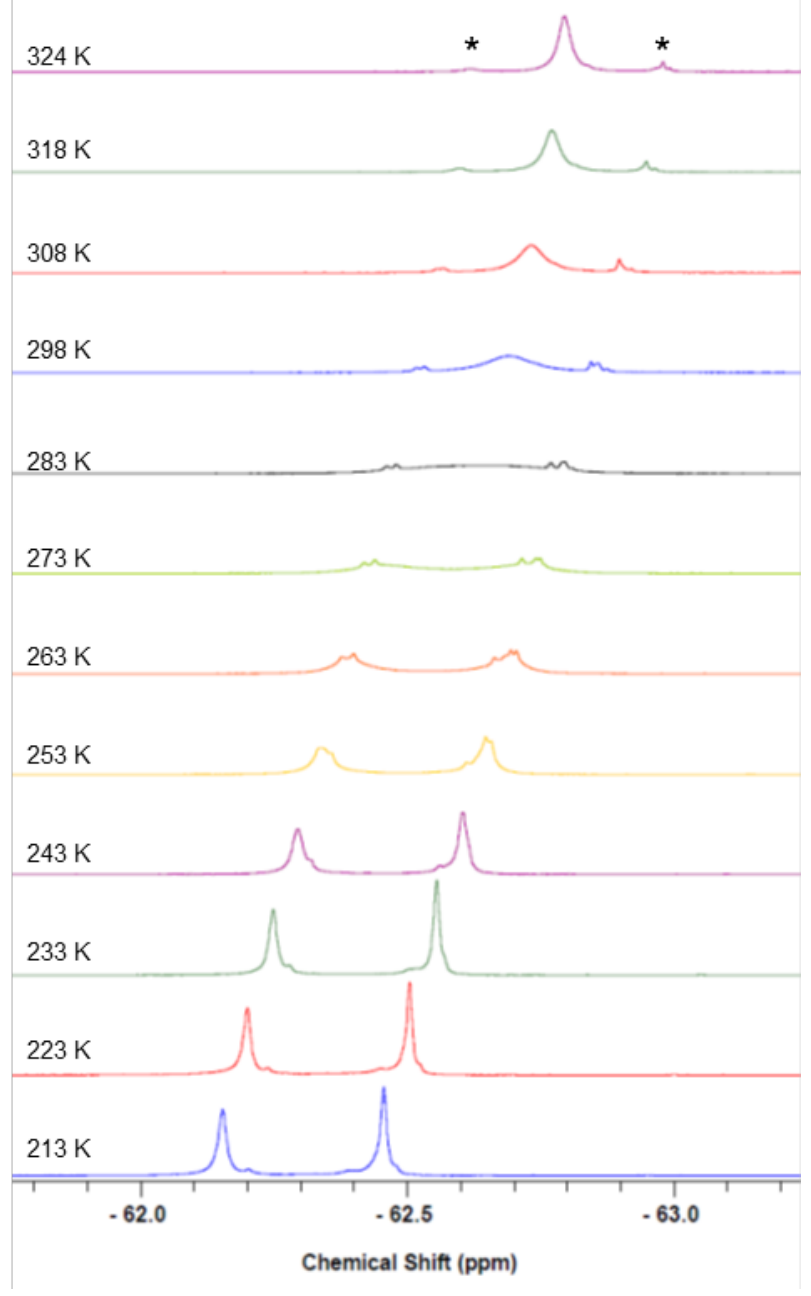

Figure 2. VT ${ }^{19} \mathrm{~F}$ NMR spectra [2]rotaxane $5\left(\mathrm{CDCl}_{3}, 377 \mathrm{MHz}\right)$. Asterisks indicate trace impurities. 
(a)

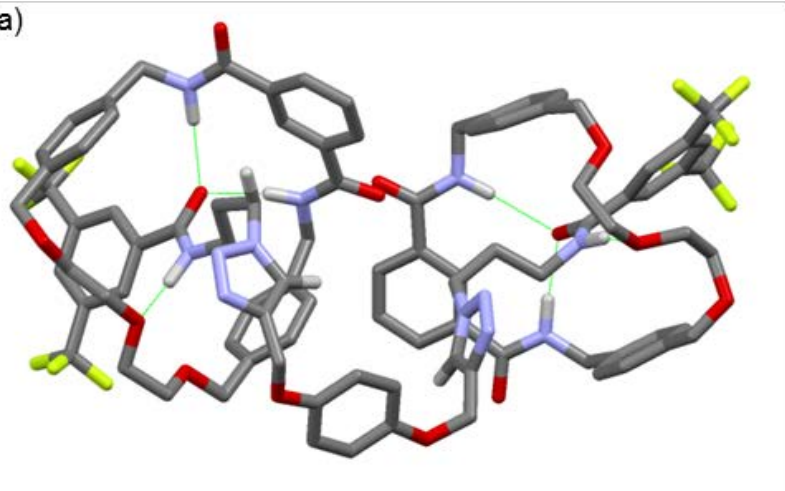

(b)

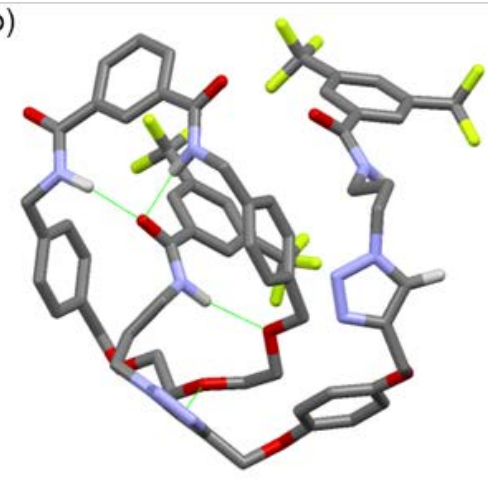

Figure 3. Minimum energy structures of (a) [3]rotaxane 4 and (b) [2]rotaxane 5.

Hydrogen bonds are represented by dashed lines. Only amide $\mathrm{N}-\mathrm{H}$ and triazole $\mathrm{C}-\mathrm{H}$ hydrogen atoms are depicted for clarity. 